Ethiopian Journal of Environmental Studies \& Management 8(Suppl. 2): 874 - 880, 2015.

ISSN:1998-0507

doi: http://dx.doi.org/10.4314/ejesm.v8i2.2S

Submitted: April 27, 2015

Accepted: October 28, 2015

\title{
CONSTRUCTION COST MODELS FOR HIGHRISE OFFICE BUILDINGS IN NIGERIA
}

\section{KADIRI, D.S.}

Department of Quantity Surveying, Obafemi Awolowo University, Ile-Ife, Nigeria

Email: deleskadiri@yahoo.com

\begin{abstract}
Existing cost estimating models offer frameworks for forecasting the probable cost of proposed construction projects. Nevertheless, they have been criticised to be either low in accuracy or slow in application. This paper describes the development of alternative costpredicting models which will be relatively faster and more accurate. Adopting the principle of cost-significant items, 15 priced bills of quantities of high rise office building projects executed or awarded in Nigeria between 2002 and 2011 were analysed. The study found that11 (29.7\%) out of 37 bill items were cost-significant accounting for $72.2 \%$ of total value of the work. The implication of the finding is that by concentrating efforts on these few items will not only reduce the stress on estimators but also enhance the accuracy of cost estimates. The resulting 11 cost-significant items were used to develop Pareto-based and multilinear regression models capable of predicting construction cost to an accuracy of 5\%.
\end{abstract}

Key Words: Cost, Highrise, Models, Nigeria, Office, Construction

\section{Introduction}

Construction projects are capital intensive and it is important to carry out cost analysis before their commencement. Construction cost estimates may be required to ascertain the level of funding required, to manage cash flow, to prepare tender prices, and to determine project viability (in the case of commercial properties) (Kelly et al., 2002). Accurate cost estimates are critical to project success (Leung et al., 2005). According to Idoro (2009), because cost, time and quality have been identified as major success indicators for construction projects, the need to execute them at optimum cost, time and quality should not be under-estimated. Numerous techniques have evolved over the years for the preparation of construction cost estimates. Harris and
McCaffer (2013) and Brook (2004) classified these techniques into two broad groups of simgle price and multiple price. The single price methods include cost per unit of accommodation, cost per square metre, cost per cubic metre and storey enclosure methods. The multiple price methods include elemental cost analysis, approximate quantities and unit rates of bills of quantities.

According to Smith and Skitmore (1991), the methods chosen for the preparation of a cost estimate depends on several criteria amongst which are the time and level of information available. However, Gould and Joyce (2000) affirmed that an estimate can only be as accurate as the information upon which it is based and the time available for its preparation. Harris and McCaffer (2013) 
therefore recommended between four to six weeks as the ideal time frame to prepare a sound cost estimate. However, Leung et al. (2005) observed that cost estimators are often pressed to produce cost estimates within a rigid and hasty timeframe. This inadequate time for the preparation of cost estimates has been claimed to be one of the major causes of their inaccuracies (Akintoye and Fitzgerald, 1999; Leung et al., 2005).

Longitudinally, there has not been much improvement on the accuracy of cost estimates in the construction industry. For example, the degree of forecast error of the single price estimating methods has been reported to be between $\pm 15 \%$ and $\pm 25 \%$ (Lock, 2003; Gould and Joyce, 2000). Similarly, Akintoye and Skitmore (1990) and Babalola and Adesanya (2013) reported accuracy of between $\pm 13 \%$ and $\pm 16 \%$ for the multiple price estimating methods. With the above variability in the accuracy of cost estimates, it was not surprising that Leung et al. (2008) have called for the need by all those involved in cost estimating process to work together to ensure the survival of construction companies.

There is need for Quantity Surveyors to devise a quick response mechanism to meet the exigencies of the construction industry in terms of quick and accurate cost estimates. Consequently, a cost estimating approach based on costsignificant items appears to be a veritable tool for achieving construction projects cost estimates which will be both fast and relatively accurate. This study therefore sought to determine the cost-significant bill items of high rise office buildings and developed Pareto-based and Regression models using the cost-significant bill items. The application of these models will enhance the preparation of cost estimates in terms of both speed and accuracy. This is because, according to Hornet et al.
(1976), cost-significant cost estimating will produce cost estimates with $\pm 5 \%$ level of accuracy.

\section{Aim and Objectives}

The aim of the study was to develop cost prediction models for high rise office buildings in Nigeria with a view to enhancing the accuracy of their cost estimates. The objectives of the study were to

a. identify and assess the cost-significant items of high rise office buildings; and

b. determine the relationships between the cost-significant items and contract sum.

\section{Methodology}

The study was carried out in Lagos and Abuja, Nigeria due to their economic, industrial and political status in Nigeria. The two cities present similar peculiarities. Lagos was until 1991 Nigeria's federal capital city while Abuja is Nigeria's current capital city. Besides, most construction industry professionals and contractors in Nigeria either have their head or branch offices in the two cities. This facilitated the collection of the relevant data for the study. However, the itinerant nature of the construction industry is such that practitioners may live in one region and operate in several other regions depending on the dictates of their capability and where their projects and clients are located.

\section{Data Collection}

Fifteen bills of quantities on executed and on-going high rise office building projects were collected and used for analysis. The projects were awarded through competitive bidding. High rise office building projects were used to get a wider spread of building elements than would have been possible with bungalow type buildings. Moreover, high rise office developments appear to be the most economic options in Lagos and Abuja for investors to recoup their expenditure on the 
high cost of land. This type of development is also in high demand by multinational companies in the eyebrow axes of Lagos and Abuja. The projects considered were executed between 2002 and 2011. Ten-year period was used for political and economic reasons. Politically, it took account of at least two administrations in Nigeria. This is because political office holders in Nigeria have four-year tenure at a time. Economically, 10- year took account of at least two economic cycles of boom and/or doom.

The bills of quantities were analysed into 37 abridged items of work similar to those used by the Building Cost Information Service (BCIS) of the Royal Institution of Chartered Surveyors (RICS). This was done to reduce the list of bill items to manageable numbers than would have been the case with the long list of work items in traditional bills of quantities. Because the projects were executed at different periods, their values were reduced to a common denominator using consumer price indices. They were then subjected to Pareto Analysis to obtain their costsignificant items from which Pareto-based and Regression models were developed.

\section{Results and Discussion \\ Cost-significant Bill Items}

Table 1 presents the summary of the cost-significant items of the 15 bills of quantities showing their mean values as a percentage of total mean value in descending order. This means that in all the 15 bills, mechanical engineering services was most cost-significant accounting for $17.8 \%$ of the total mean value; it is followed by electrical engineering installation with $13.1 \%$ of total bill value; and so on. On overall, 11 items were cost-significant out of the 37 items analysed. This represents $29.7 \%$ of total bill items. From these results, it is instructive to note that services account for $30.9 \%$ of total cost. This is in agreement with Babalola and Adesanya (2009) which reported that services was $30 \%$ of estimated cost of buildings. However, the results cannot be related to the previous works of Harmer (1983) and Allman (1988) because they were based on trades (work sections) instead of work items. This study is therefore more representative of the modern trend in cost analysis and cost planning which are based on elements rather than on trades. A trade could cover so many elements and thus is not easily amenable to alterations during design development.

The fact that the structural elements did not score high in cost significance is also not surprising. This is because of the need to reduce overall dead load in high rise buildings. This also explains why curtain walling is cost significant. Thus, the need to ensure rigidity in the structural elements accounts for why reinforcement in frame and upper floors are cost significant.

\section{Pareto-based Model}

Table 2 presents the cumulative values of the cost-significant items as a percentage of total bill value. From the table, the cumulative value of the 11 costsignificant items accounted for $72.2 \%$ of the total value. The 11 cost-significant items represent $29.7 \%$ of the total (37) number of bill items. In other words, $29.7 \%$ items accounted for $72.2 \%$ of estimated value or contract sum. Thus the Pareto-based model is $72 / 30$ to the nearest whole numbers. That is, $30 \%$ of bill items accounted for $72 \%$ of contract value. It can therefore be said that Pareto Rule (80/20 Rule) did not hold. This relationship compares well with the work of Saket (1986) which found that $22.6 \%$ of bill items accounted for $76.5 \%$ of estimated cost. 
Table 1: CSIs of High-rise Office Buildings

\begin{tabular}{llll}
\hline CSIs & Mean Values & Percentage of Total & Rank \\
\hline Mechanical Services & $194,773,149.51$ & 17.8 & 1 \\
Electrical Services & $143,115,697.33$ & 13.1 & 2 \\
Preliminaries & $88,641,470.76$ & 8.1 & 3 \\
Floor Finishings & $66,267,790.49$ & 6.1 & 4 \\
Wall Finishings & $55,645,059.44$ & 5.1 & 5 \\
Reinforcements in Frame & $45,628,283.87$ & 4.2 & 6 \\
Curtain Walls & $44,670,256.49$ & 4.1 & 7 \\
External Works & $44,293,668.90$ & 4.1 & 8 \\
Windows & $37,798,804.05$ & 3.5 & 9 \\
Reinforcement in Upper Floors & $37,245,793.29$ & 3.4 & 10 \\
Concrete in Substructure & $30,701,915.92$ & 2.8 & 11 \\
\hline
\end{tabular}

Total Mean Value $=$ N 1,093.0Million

Table 2: Relationship Between CSIs and Total Const. Cost

\begin{tabular}{lllll}
\hline $\begin{array}{l}\text { Rank of } \\
\text { CSI }\end{array}$ & $\begin{array}{l}\text { \% of Total } \\
\text { Bill Items }\end{array}$ & $\begin{array}{l}\text { Value of CSI } \\
\text { (N'million) }\end{array}$ & $\begin{array}{l}\text { Cum. Value of } \\
\text { CSI (N'million) }\end{array}$ & $\begin{array}{l}\text { \% of Total Const. } \\
\text { Cost }\end{array}$ \\
\hline 1 & 2.7 & 194.8 & 194.8 & 17.8 \\
2 & 5.4 & 143.1 & 337.9 & 30.9 \\
3 & 8.1 & 88.6 & 426.5 & 39.0 \\
4 & 10.8 & 66.2 & 492.7 & 45.1 \\
5 & 13.5 & 55.6 & 548.3 & 50.2 \\
6 & 16.2 & 45.6 & 593.9 & 54.3 \\
7 & 18.9 & 44.7 & 638.6 & 58.4 \\
8 & 21.6 & 44.3 & 682.9 & 62.5 \\
9 & 24.3 & 37.8 & 720.7 & 65.9 \\
10 & 27.0 & 37.2 & 757.9 & 69.3 \\
11 & 29.7 & 30.7 & 788.6 & 72.2 \\
\hline
\end{tabular}

Total Mean Value of Bills 1 to $15=\mathrm{N} 1,093.0$ Million

Total No. of Items $=37$

\section{Regression Model}

To develop a Regression model, the data set in Appendix 1 were used. The proposition being tested by these data was that the estimated construction cost of a building is dependent on the costs of its significant items. Therefore, from the data set, a simultaneous multiple regression procedure of the Statistical Package for Social Sciences (SPSS) was used to develop a regression model taking the form: $Y=f\left(a_{1} x_{1}+a_{2} x_{2} \ldots+a_{n} x_{n}\right)$; where, $\mathrm{Y}$ is estimated construction cost, $\mathrm{a}_{1}$ to $\mathrm{a}_{\mathrm{n}}$ are the coefficients of the 11 cost- significant items and $x_{1}$ to $x_{n}$ are the 11 cost-significant items.

From the coefficients in Table 3 a regression equation was derived as follows: Estimated Construction cost $=$ $50.019+1.370$ (cost of mechanical engineering installations) +1.347 (cost of electrical engineering installation) +3.572 (cost of preliminaries) - .416 (cost of floor finishings) +2.892 (cost of wall finishings) +.723 (cost of Reinforcement in Frames) .219 (cost of curtain wall) +1.103 (cost of external works) -.476 (cost of windows) + 3.219 (cost of reinforcement in upper floors) +.915 (cost of concrete in substructure). 
Table 3: Coefficients of CSIs

\begin{tabular}{ll}
\hline Variables & Coefficients \\
\hline (Constant) & 50.019 \\
Mechanical Engineering $\left(\mathrm{x}_{1}\right)$ & 1.370 \\
Electrical Engineering $\left(\mathrm{x}_{2}\right)$ & 1.347 \\
Preliminaries $\left(\mathrm{x}_{3}\right)$ & 3.572 \\
Floor Finishings $\left(\mathrm{x}_{4}\right)$ & -.416 \\
Wall Finishings $\left(\mathrm{x}_{5}\right)$ & 2.892 \\
Reinforcement in Frames $\left(\mathrm{x}_{6}\right)$ & .723 \\
Curtain Walls $\left(\mathrm{x}_{7}\right)$ & -.219 \\
External Works $\left(\mathrm{x}_{8}\right)$ & 1.103 \\
Windows $\left(\mathrm{x}_{9}\right)$ & -.476 \\
Reinforcement in Upper floors $\left(\mathrm{x}_{10}\right)$ & 3.219 \\
Concrete in Substructure $\left(\mathrm{x}_{11}\right)$ & .915 \\
\hline
\end{tabular}

Dependent Variable: Total Construction Cost (Y)

\section{Conclusions}

The cost-significant items of high-rise office buildings executed in Nigeria between 2002 and 2011 were mechanical engineering installations, electrical engineering installations, preliminaries items, floor finishings, wall finishings and reinforcement in frames. Others were curtain walls, external works, windows, reinforcement in upper floors and concrete in substructure.

The percentage contributions of the cost-significant bill items to estimated contract cost were, respectively, mechanical engineering services (17.83), electrical engineering services (13.09), preliminary items (8.11), floor finishings (6.06), wall finishings (5.09) and reinforcement in frame (4.17). Others were curtain walls (4.09), external works (4.05), windows (3.46), reinforcement in upper floors (3.41) and concrete in substructure (2.81).

The 72/30 Pareto-based model developed for predicting the contract value of high rise office building projects implied that $72 \%$ of the estimated costs of high-rise office buildings were accounted for by $30 \%$ of bill items.

The regression model developed for predicting the contract sum of high-rise office buildings was: $\mathrm{Y}=50.019+1.370$ $\mathrm{CMEI}+1.347$ CEEI + 3.572 CP - .416 $\mathrm{CFF}+2.892 \mathrm{CWF}+.723 \mathrm{CRIF}-.219$ $\mathrm{CCW}+1.103 \mathrm{CEW}-.476 \mathrm{CW}+3.219$ CRIUF + .915 CLE; where: Y is estimated total cost of building, 50.019 is a constant, CMEI is cost of mechanical engineering installations, CEEI is cost of electrical engineering installations, $\mathrm{CP}$ is cost of preliminaries items, $\mathrm{CFF}$ is cost of floor finishings, $\mathrm{CWF}$ is cost of wall finishings, CRIF is cost of reinforcement in frame, $\mathrm{CCW}$ is cost of curtain walling, CEW is cost of external works, CW is cost of windows, CRIUF is cost of reinforcement in upper floors and CLE is cost of lift installations.

\section{References}

Akintoye, A. and Fitzgerald, E. (1999). A survey of current cost estimating practices in the UK, Construction Management and Economics, 18: 161- 172.

Akintoye, A. and Skitmore, R.M. (1990). Analysis of UK tender price levels, American Association of Cost Engineers, 7: 1-7.

Allman, I. (1998). Significant items estimating. Chartered Quantity Surveyors, Sept: 24-25 
Babalola, O. and Adesanya, D.A. (2009). An evaluation of the level of accuracy of mechanical service cost estimates in Nigeria. Construction Research Journal, 2: 12-19.

Brook, M. (2004). Estimating and Tendering for Construction Work $\left(2^{\text {nd }}\right.$ ed.). Oxford: Butterworth Heinemann.

Gould, F.E. and Joyce, N.E. (2000). Construction Project Management. New Jersey: Prentice Hall

Harmer, S. (1983). Identifying significant bill items. Chartered Quantity Surveyor. $95-96$.

Harris, F. and McCaffer, R. (2013). Modern Construction Management ( $7^{\text {th }}$ ed.). Oxford: Blackwell Publishing.

Idoro, G. I. (2009). Causes of timeoverrun in construction projects in Nigeria. Construction Research Journal, 2: 74-87.

Kelly, J., Morledge, R. and Wilkinson, S. (2002). Best value in construction. Oxford: Blackwell Science \& Royal Institution of Chartered Surveyors.
Leung, M.Y., Ng, S.T. and Skitmore, R.M. (2005). Critical stressors influencing construction estimators in Hong Kong. Construction Management and Economics. 23(1): 33-43.

Leung, M.Y., Zhang, H. and Skitmore, R.M. (2008). The effects of organisational supports in the estimation process on the stress of construction cost engineers, Journal of Construction Engineering and Management, 134(2): 84-93.

Lock, D. (2003). Project Management $\left(8^{\text {th }}\right.$ ed.). Hampshire: Gower Publishing Ltd.

Saket, M.M. (1986). Cost significance applied to estimating and control of construction projects. A Doctoral Thesis submitted to the department of civil engineering, University of Dundee.

Smith, M. and Skitmore, M. (1991). Authomatic pricing of bills of quantities for construction work, Department of Surveying, University of Salford, Salford. 


\section{APPENDIX I}

Cost-Significant Items

\begin{tabular}{|c|c|c|c|c|c|c|c|c|c|c|c|c|}
\hline Bill No & $\begin{array}{l}\text { Total } \\
\text { Const. } \\
\text { Cost }\end{array}$ & $\begin{array}{l}\text { Mech. } \\
\text { Eng } x_{1}\end{array}$ & $\begin{array}{l}\text { Elect. } \\
\text { Eng. } \\
\mathrm{X}_{2}\end{array}$ & $\begin{array}{l}\text { Prelim.. } \\
\mathrm{X}_{3}\end{array}$ & Flr Fin. $\mathrm{X}_{4}$ & $\mathrm{X}_{5}$ & $\begin{array}{l}\text { Rft. In } \\
\text { frame } x_{6}\end{array}$ & $\begin{array}{l}\text { Curt. } \\
\text { Wall } \\
\mathrm{X}_{7}\end{array}$ & $\begin{array}{l}\text { Ext. } \\
\text { wks. } \\
X_{8}\end{array}$ & $\begin{array}{l}\text { Wind } \\
\mathrm{s} \mathrm{X}_{9}\end{array}$ & $\begin{array}{l}\text { Rft in Upp } \\
\text { Flr } \mathrm{x}_{10}\end{array}$ & $\begin{array}{l}\text { Conc. in } \\
\text { sub. } x_{11}\end{array}$ \\
\hline 1 & 1264.4 & 386.8 & 38.9 & 118.3 & 0 & 52.5 & 0 & 0 & 62.1 & 104.4 & 0 & 42.4 \\
\hline 2 & 393.3 & 64.4 & 80 & 23.3 & 23.9 & 16.6 & 20.2 & 0 & 14.6 & 0 & 0 & 0 \\
\hline 3 & 3004.5 & 639.3 & 377.4 & 266.5 & 271 & 0 & 137.7 & 352.2 & 0 & 0 & 220.9 & 0 \\
\hline 4 & 3567.6 & 542.3 & 433.8 & 335.1 & 141.9 & 237.2 & 303.9 & 0 & 0 & 0 & 0 & 162.1 \\
\hline 5 & 1424.8 & 202.8 & 251.6 & 94 & 82.2 & 126.2 & 0 & 0 & 43.4 & 191.5 & 44.1 & 0 \\
\hline 6 & 898.4 & 0 & 0 & 126.4 & 88.4 & 87.8 & 42.9 & 0 & 114.5 & 38.4 & 0 & 41.8 \\
\hline 7 & 290.5 & 31.4 & 28.3 & 13 & 24 & 12 & 0 & 27.4 & 14.5 & 0 & 25.9 & 10.1 \\
\hline 8 & 1781.1 & 441.6 & 405.3 & 157.8 & 57.8 & 0 & 0 & 240 & 80.6 & 0 & 0 & 0 \\
\hline 9 & 436.0 & 63.3 & 76.3 & 23.6 & 35.6 & 15.0 & 0 & 0 & 72.1 & 0 & 0 & 18.9 \\
\hline 10 & 520.7 & 131.3 & 101.5 & 23.6 & 25.8 & 20.3 & 0 & 0 & 0 & 0 & 0 & 34.1 \\
\hline 11 & 1376.9 & 252.9 & 168.9 & 70.7 & 115.7 & 97.1 & 0 & 0 & 52.3 & 84.5 & 75.5 & 0 \\
\hline 12 & 385.1 & 15 & 14.1 & 13.1 & 16.2 & 31.8 & 51.0 & 0 & 45.6 & 19.0 & 18.3 & 15.3 \\
\hline 13 & 356.1 & 67.2 & 46.8 & 27.1 & 35.6 & 12.8 & 0 & 0 & 17.4 & 29.3 & 0 & 12.5 \\
\hline 14 & 486.5 & 60.8 & 101.5 & 21.5 & 28.9 & 18.7 & 0 & 0 & 0 & 0 & 17.1 & 25.3 \\
\hline 15 & 209.6 & 18.9 & 19.4 & 15.6 & 19.5 & 9.8 & 0 & 0 & 36.2 & 10 & 0 & 7.5 \\
\hline
\end{tabular}

Statistical Analysis of the Relationship between Total Construction Cost and Cost of CSIs

Cost items are in (\#' Million) 